\title{
Evaluation of J-Integral for Surface Cracked Plates under Biaxial Loading Using Extended Reference Stress Method
}

\author{
Naoki Miura' ${ }^{1)}$ and Yukio Takahashi ${ }^{1)}$ \\ 1) Central Research Institute of Electric Power Industry, Tokyo, Japan
}

\begin{abstract}
In this paper, reference stress solutions for plates with semi-elliptical surface cracks were firstly reviewed, and the applicability of the solutions was examined through the comparison with finite element analysis results under uniaxial loading. Next, an extended reference stress method was newly developed to evaluate J-integral for cracked plates under biaxial loading. The predictive accuracy of the method was validated through the comparison with finite element analysis results under biaxial loading.
\end{abstract}

\section{INTRODUCTION}

Conventional creep-fatigue crack growth analysis or unstable fracture analysis has been conducted under uniaxial stress condition. However, actual plant components come into various multiaxial stress conditions. Therefore, the evaluation of fracture mechanics parameter of cracked bodies under multiaxial stress conditions is essentially needed for the accurate estimation of crack growth behavior and fracture behavior. In this paper, three-dimensional finite element analysis for surface cracked plates subjected to biaxial loading was conducted to see the effect of biaxial loading on J-integral. An extended reference stress method was then proposed to evaluate J-integral under biaxial loading, and the applicability of the proposed method was validated through the comparison with the results of the finite element analysis.

\section{REFERENCE STRESS SOLUTIONS FOR SURFACE CRACKED PLATES}

\section{Review of Reference Stress Solutions and Derivation of Limit Load Solutions}

Several reference stress solutions have been proposed for plates with a semi-elliptical surface crack subjected to uniaxial tension and bending, based on individual theoretical model, yielding condition, and numerical analysis (Willoughby and Davey [1], Sattari-Far [2], Sattari-Far and Dillström [3], Goodall and Webster [4], and Lei [5]). The reference stress, $\sigma_{\text {ref, }}$ can be generally expressed as

$$
\sigma_{r e f}=f\left(\sigma_{m}, \sigma_{b}, a / t, a / c, c / b\right)
$$

where $\sigma_{m}$ and $\sigma_{b}$ are the membrane stress and the bending stress applied to the plate, $a$ and $c$ are the crack depth and the half crack length, and $t$ and $b$ are the plate thickness and the half plate width, respectively.

Considering that surface cracked plates are subjected to pure tension, limit load, $P_{L}$, can be estimated by the following equation using $\sigma_{r e f}$,

$$
P_{L}=\left(\sigma_{y} / \sigma_{r e f}\right) P
$$

where $\sigma_{y}$ is the yield stress. The tensile load, $P$, is given by

$$
P=2 b t \sigma_{m}
$$

Supposing that the limit load for uncracked plate, $P_{L 0}$, is defined as

$$
P_{L 0}=2 b t \sigma_{y}
$$

The normalized limit load, $P_{L} / P_{L 0}$, can be calculated by

$$
P_{L} / P_{L 0}=\sigma_{m} / \sigma_{r e f}
$$

Based on the above procedure, limit load solutions for surface cracked plates subjected to pure tension can be reduced as shown in Table 1, in which the solutions are derived from the

\begin{tabular}{|c|c|c|c|}
\hline \multicolumn{2}{|c|}{ Reference } & Yielding Definition & Normalized Limit Load Solution \\
\hline \multirow{2}{*}{$\begin{array}{c}\text { Willoughby } \\
\text { \& Davey } \\
{[1]} \\
\end{array}$} & $\begin{array}{c}\text { with Bending } \\
\text { Constraint }\end{array}$ & \multirow{2}{*}{$\begin{array}{l}\text { 2D Local Yielding } \\
\text { Substituted for } \\
\text { 3D Global Yielding }\end{array}$} & $P_{L} / P_{L 0}=1-\zeta$ \\
\hline & $\begin{array}{c}\text { w/o Bending } \\
\text { Constraint } \\
\end{array}$ & & $P_{L} / P_{L 0}=\sqrt{2 \zeta^{2}-2 \zeta+1}-\zeta$ \\
\hline \multicolumn{2}{|c|}{ Sattari-Far [2] } & Local Yielding & $P_{L} / P_{L 0}=1-\zeta$ \\
\hline \multicolumn{2}{|c|}{ Sattari-Far \& Dillström [3] } & $\begin{array}{c}\text { Through-Thickness } \\
\text { Yielding } \\
\end{array}$ & $P_{L} / P_{L 0}=(1-\zeta)^{0.43}$ \\
\hline \multicolumn{2}{|c|}{ Goodall \& Webster [4] } & Global Yielding & $P_{L} / P_{L 0}=\sqrt{2 \alpha^{2} \beta-2 \alpha \beta+1-\alpha \beta}$ \\
\hline \multicolumn{2}{|c|}{ Lei [5] } & Global Yielding & $P_{L} / P_{L 0}=\sqrt{2 \alpha^{2} \beta-2 \alpha \beta+1}-\alpha \beta$ \\
\hline \multicolumn{4}{|c|}{$\begin{array}{l}\frac{a}{t} \frac{c}{c+t}, \text { for } b \geq c+t \\
\frac{a}{t} \frac{c}{b}, \text { for } b<c+t\end{array}, \quad \alpha=\frac{a}{t}, \quad \beta=\frac{c}{b}$} \\
\hline
\end{tabular}
reference stress solutions in Eq. (1) with $\sigma_{b}=0$. It can be seen that the Willoughby's solution with bending constraint
Table 1 Summary of Limit Load Solutions for Surface Cracked Plates 


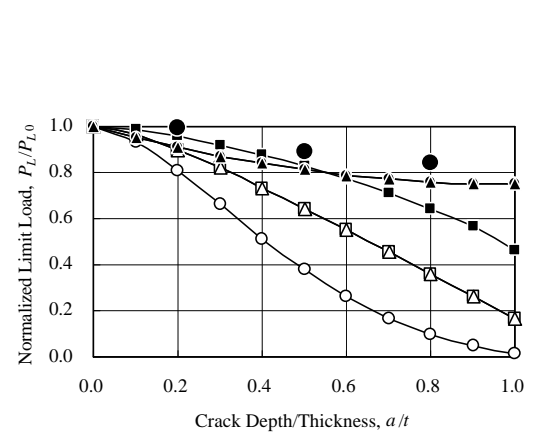

(a) For $a / c=0.2$

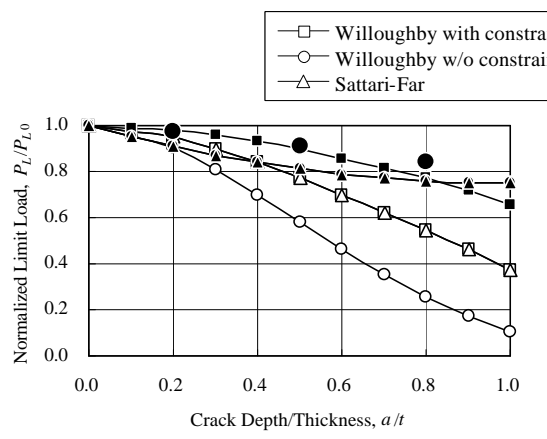

(b) For $a / c=0.6$

Fig. 1 Comparison of Normalized Limit Load Solutions
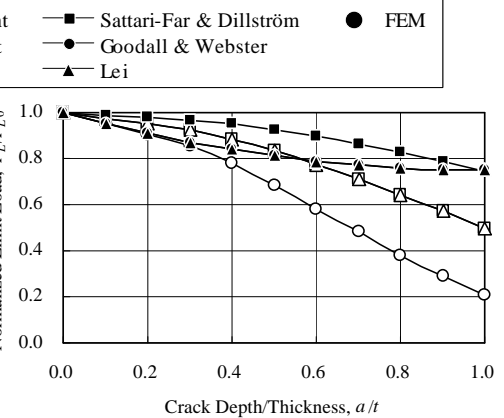

(c) For $a / c=1.0$

[1] is identical with the Sattari-Far's solution [2], and the Goodall's solution [4] is identical with the Lei's solution [5] , respectively.

Figures 1(a) to (c) show the comparison of the normalized limit load solutions for different values of $a / c$ and $a / t$. In the Goodall's solution [4] and the Lei's solution [5], $P_{L} / P_{L 0}$ seems to be saturated at higher alt, while it decreases with increasing $a /$ $t$ in other solutions [1 to 3].

\section{Availability of Limit Load Solutions}

Plastic collapse loads were calculated by elastic-perfectly plastic finite element analyses for surface cracked plates subjected to pure tension, and the results were compared with the above limit load solutions to see the availability of the solutions. The aspect ratio, $a / c$, was set to 0.2 and 0.6 , and the normalized crack depth, a/t, was set to $0.2,0.5$, and 0.8 . The normalized crack length, $c / b$, was fixed to 0.25 (see the later section for detailed analysis condition).

$P_{L} / P_{L 0}$ values obtained from the finite element analysis are plotted on Figs. 1(a) and (b), compared with the associated limit load solutions. The Wiloughby's solutions (with/without bending constraint) [1] and the Sattari-Far's solution [2] give excessively small limit loads. In contrast, the Sattari-Far and Dillström's solution [3], the Goodall's solution [4], and the Lei's solution [5] seem to provide reasonable relations between $P_{L} / P_{L 0}$ and a/t. Assuming that the finite element results are exact, the average error of the predicted $P_{L} / P_{L 0}$ was $9 \%$ for the Sattari-Far and Dilllstörm's solution and $11 \%$ for the Lei's solution. Thus, the Sattari-Far and Dilllstörm's solution or the Lei's solution (which comprises the Goodall's solution) seems to be appropriate for the cases examined.

\section{FINITE ELEMENT ANALYSIS OF SURFACE CRACKED PLATES UNDER BIAXIAL LOADING}

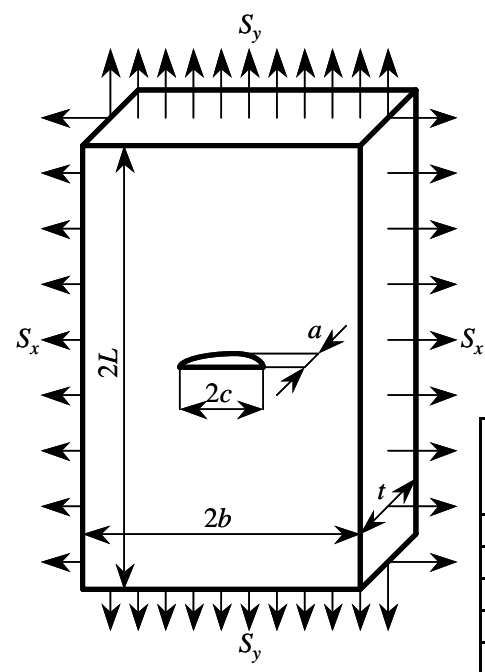

Fig. 2 Surface Cracked Plate Subjected to Biaxial Loading

\section{Analysis Condition}

Three-dimensional finite element analyses of surface cracked plates were conducted. Figure 2 shows the analysis model. The half plate width, $b$, the half plate length, $L$, and the half crack length, $c$, were fixed to $100 \mathrm{~mm}, 400 \mathrm{~mm}$, and $25 \mathrm{~mm}$, respectively. The aspect ratio, $a / c$, was set to 0.2 and 0.6 , and the normalized crack depth, alt, was set to $0.2,0.5$, and 0.8 . Table 2 shows the list of crack sizes.

The analysis was conducted using "MARC" with twenty-noded solid elements. Both the remote uniform stress perpendicular to the crack, $S_{y}$, and the remote uniform stress parallel to the crack, $S_{x}$, were applied. The final $S_{x}$ was varied from $-400 \mathrm{MPa}$ to

Table 2 List of Crack Sizes

\begin{tabular}{|c|c|c|c|}
\hline Case No. & $\begin{array}{c}\text { Crack Depth } \\
\text { Ratio } \\
a / t\end{array}$ & $\begin{array}{c}\text { Aspect } \\
\text { Ratio } \\
a / c\end{array}$ & $\begin{array}{c}\text { Crack Length } \\
\text { Ratio } \\
c / b\end{array}$ \\
\hline 1 & 0.2 & \multirow{2}{*}{0.2} & \\
\hline 2 & 0.5 & \multirow{2}{*}{0.25} \\
\hline 3 & 0.8 & \multirow{2}{*}{0.6} & \\
\hline 4 & 0.2 & & \\
\hline 5 & 0.5 & & \\
\hline 6 & 0.8 & &
\end{tabular}

Table 3 List of Loading Conditions

\begin{tabular}{|c|c|c|c|}
\hline \multirow[b]{2}{*}{ Case No. } & \multicolumn{2}{|c|}{ Remote Uniform Stress ${ }^{*}$} & \multirow{2}{*}{$\begin{array}{c}\text { Stress Ratio } \\
S_{x} / S_{y}\end{array}$} \\
\hline & $\begin{array}{c}\text { x-Direction } \\
S_{x}, \mathrm{MPa}\end{array}$ & $\begin{array}{c}\text { y-Direction } \\
S_{y}, \mathrm{MPa}\end{array}$ & \\
\hline $\mathrm{A}$ & -400 & 200 & -2.0 \\
\hline $\mathrm{B}$ & -200 & 200 & -1.0 \\
\hline $\mathrm{C}$ & -100 & 200 & -0.5 \\
\hline $\mathrm{D}$ & 0 & 200 & 0.0 \\
\hline $\bar{E}$ & 100 & 200 & 0.5 \\
\hline $\mathrm{F}$ & 200 & 200 & 1.0 \\
\hline $\mathrm{G}$ & 400 & 200 & 2.0 \\
\hline
\end{tabular}


$400 \mathrm{MPa}$, and the final $S_{y}$ was fixed to $200 \mathrm{MPa}$. The stresses in both directions were loaded proportionally. Table 3 shows the list of loading conditions. The results on Case D in the table were used in the preceding section to see the availability of the limit load solutions under uniaxial loading.

Two types of stress-strain relations were prepared. One was the elastic-perfectly plastic stress-strain relation, whose results were used to validate the proposed limit load solution under biaxial loading, and the other was elastic-plastic stressstrain relation, whose results were applied to validate the proposed $J$-evaluation method under biaxial loading. Table 4 shows the material properties used in the analyses. For the elastic-plastic analysis, $J$-integrals both at the deepest points and at the surface points were evaluated by path-integrals. Figure 3 shows an example of finite element mesh together with $J$-integral paths.

\section{Results of Elastic-Perfectly Plastic Analysis}

The typical relations between $S_{y}$ and crack-opening displacement (COD) with different stress ratio, $S_{x} / S_{y}$, are shown in Figs. 4(a) to (c). The relations in smaller COD ranges show almost identical curves in spite of the different $S_{x} / S_{y}$. The values of $S_{y}$ converge to a constant level at larger COD, which are corresponding to the plastic collapse on the global yielding.

Figures 5 shows the relation between the normalized plastic collapse load, $P_{L, \text { biaxial }} / P_{L, \text { uniaxial }}$, and $S_{x} / S_{y}$, where $P_{L, \text { biaxial }}$ is the plastic collapse load obtained from the analysis for a specific $S_{x} / S_{y}$, and $P_{L \text {,uniaxial }}$ is the plastic collapse load at $S_{x}=0$. $P_{L, b i a x i a l}$ $P_{L, \text { uniaxial }}-S_{x} / S_{y}$ relations are not significantly affected by a/t or $a / c$, and the normalized plastic collapse loads take the maximum values at $S_{x} / S_{y}=0.5$

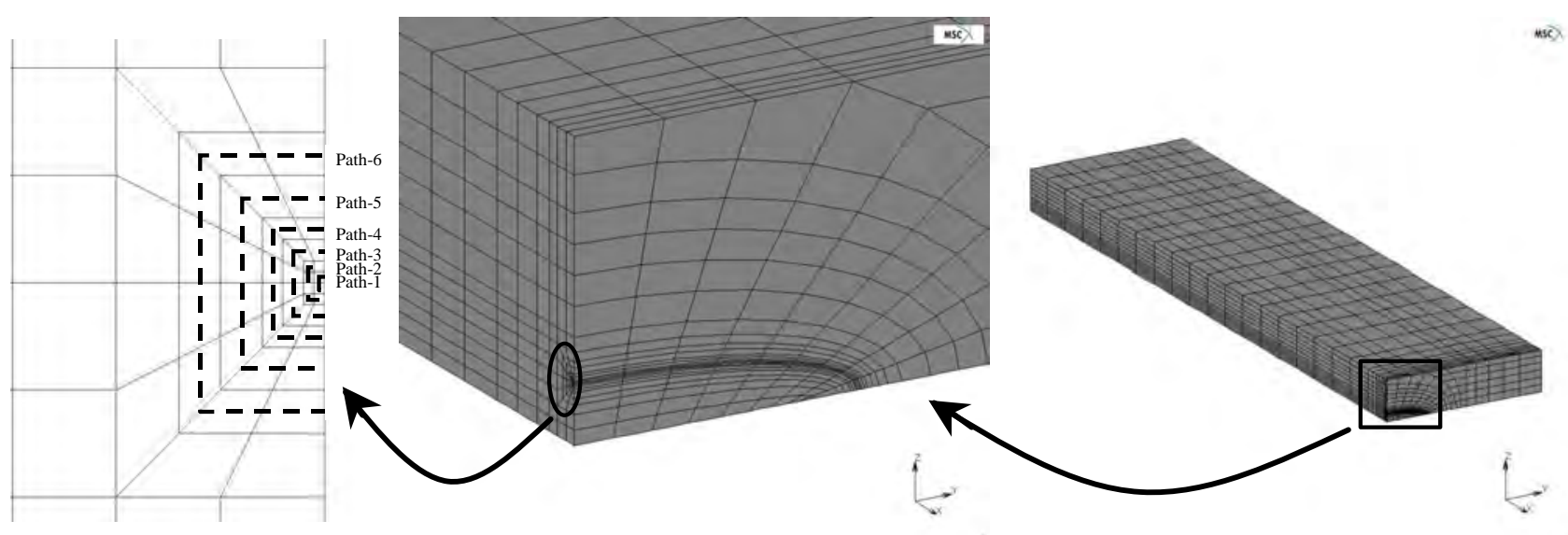

Fig. 3 Example of Finite Element Mesh and $J$-Integral Paths $($ Case $1, a / c=0.2, a / t=0.2)$

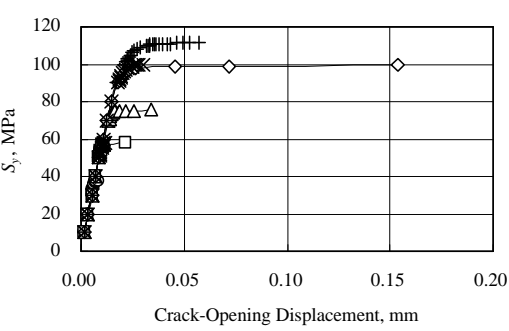

(a) Case $1(a / c=0.2, a / t=0.2)$

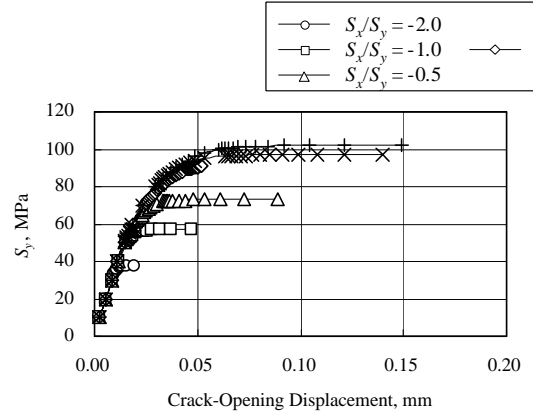

(b) Case $2(a / c=0.2, a / t=0.5)$

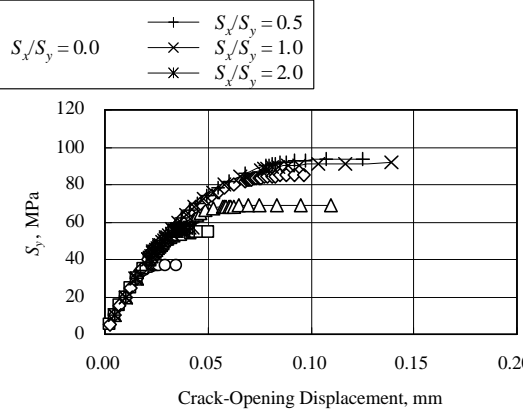

(c) Case $3(a / c=0.2, a / t=0.8)$

Fig. 4 Typical Relations between $S_{y}$ and COD from Elastic-Perfectly Plastic Analysis 


\section{Results of Elastic-Plastic Analysis}

Prior to the $J$-evaluations, the path-independency of $J$ integrals was individually seen. The $J$-integral values obtained from different paths were coincident one another. In this analysis, $J$-integral obtained from the most outside path (Path-6 in Fig. 3), was used as the value of finite element analysis, which variations from the average of the $J$-integrals were less than $2 \%$.

Figures 6(a) to (c) show the typical relations between $S_{y}$ and load-point displacement with different stress ratio, $S_{x} / S_{y}$. Smaller $S_{x} / S_{y}$ gives higher load-point displacement for a certain value of $S_{y}$. This means that the compressive stress parallel to the crack promotes axial deformation, and the tensile stress parallel to the crack restrains axial deformation.

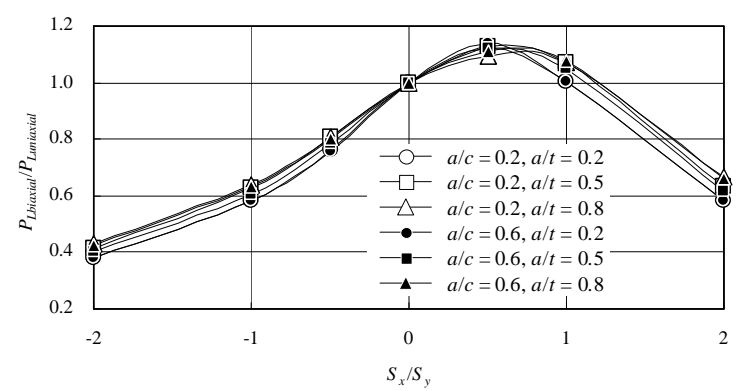

Fig. 5 Relations between Normalized Plastic Collapse Load and $S_{x} / S_{y}$ from Elastic-Perfectly Plastic Analysi

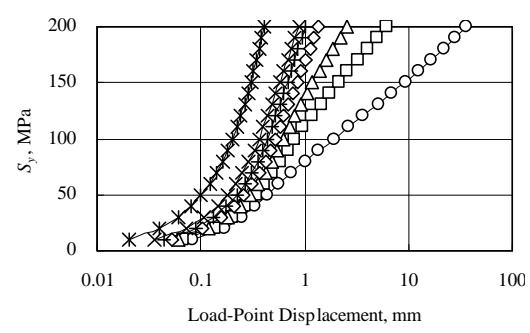

(a) Case $1(a / c=0.2, a / t=0.2)$

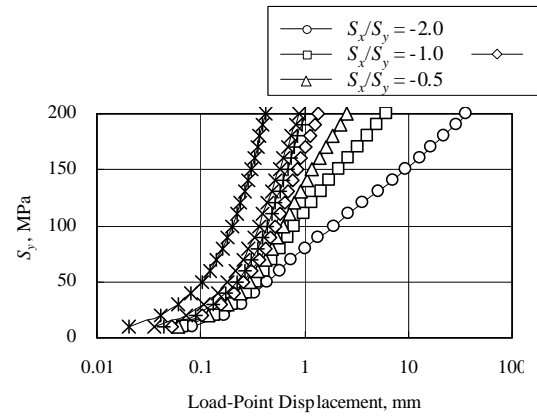

(b) Case $2(a / c=0.2, a / t=0.5)$
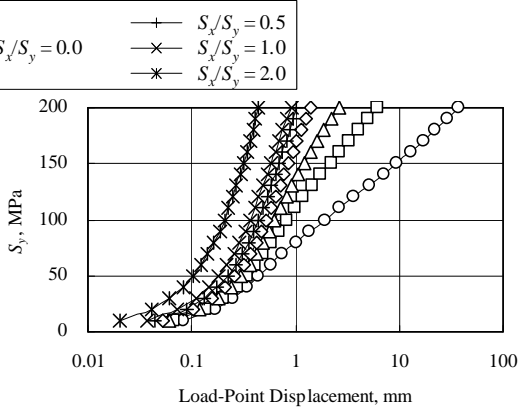

(c) Case $3(a / c=0.2, a / t=0.8)$

Fig. 6 Relations between $S_{y}$ and Load-Point Displacement from Elastic-Plastic Analysis

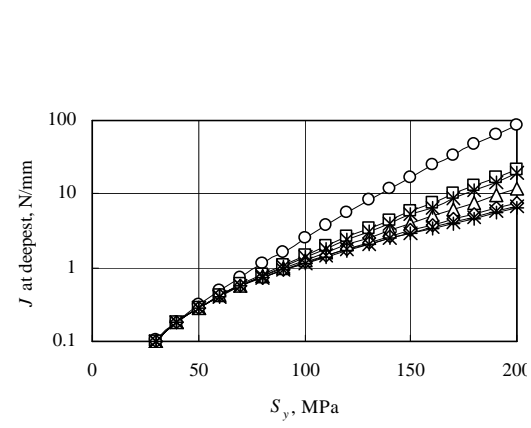

(a) Case $1(a / c=0.2, a / t=0.2)$

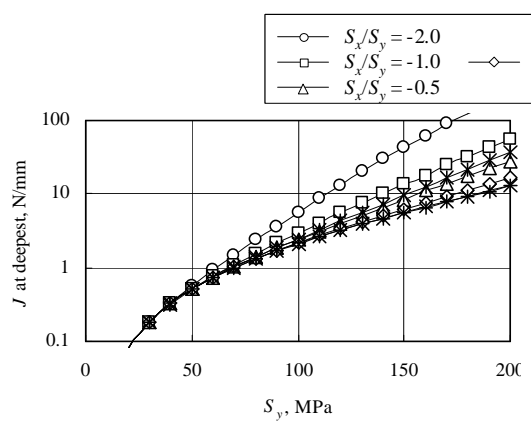

(b) Case $2(a / c=0.2, a / t=0.5)$
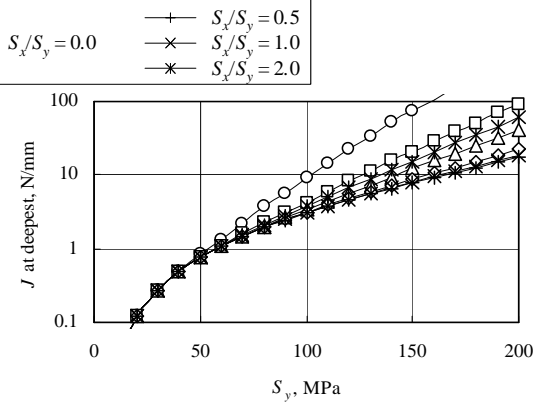

(c) Case $3(a / c=0.2, a / t=0.8)$

Fig. 7 Relations between $J$-Integral at Deepest Point and $S_{y}$ from Elastic-Plastic Analysis

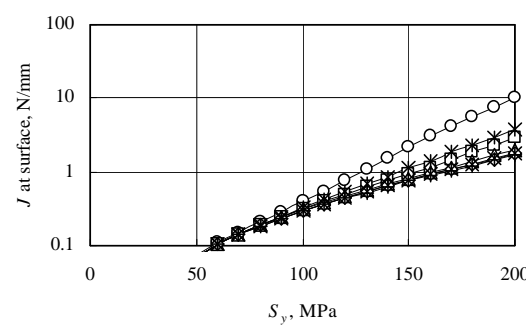

(a) Case $1(a / c=0.2, a / t=0.2)$

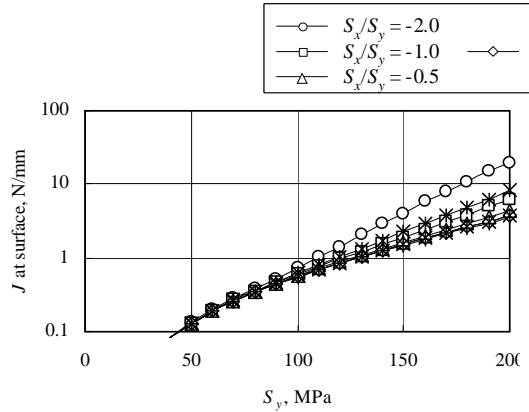

(b) Case $2(a / c=0.2, a / t=0.5)$
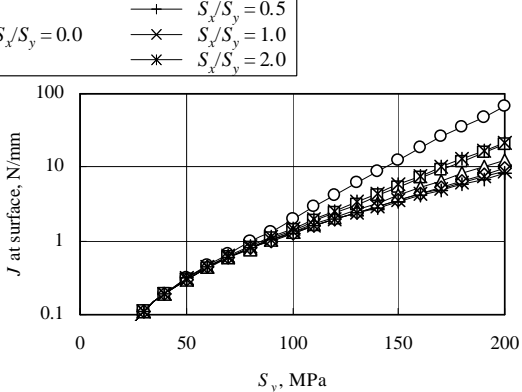

(c) Case $3(a / c=0.2, a / t=0.8)$

Fig. 8 Relations between $J$-Integral at Surface Point and $S_{y}$ from Elastic-Plastic Analysis 
The typical relations between $J$-integral at the deepest point and $S_{y}$, and the typical relations between $J$-integral at the surface point and $S_{y}$ are shown in Figs. 7(a) to (c) and Figs. 8(a) to (c), respectively. $J$-integral is smoothly increasing with increasing $S_{y}$, however, the increasing rate is significantly affected by $S_{x} / S_{y}$. The contribution of $S_{x} / S_{y}$ is not monotonic Figures 9(a) and (b) show the effect of $S_{x} / S_{y}$ on $J$-integral at the final loading state $\left(S_{y}=200 \mathrm{MPa}\right)$. The level of $J$-integral value varies depending on crack sizes, however, the effect of $S_{x} / S_{y}$ on $J$-integral is qualitatively identical without regard to crack sizes or evaluation points (deepest point/surface point). $J$-integral takes minimum value when $S_{x} / S_{y}$ ranges between 0 and 1 . It is interesting that the effect of $S_{x} / S_{y}$ on $J$-integral is complementary to the effect of $S_{x} / S_{y}$ on normalized plastic collapse load shown in Fig. 5.

\section{PROPOSAL OF EXTENDED REFERENCE STRESS METHOD UNDER BIAXIAL LOADING}

\section{Limit Load Solution under Biaxial Loading}

Considering a body with the yielding stress, $\sigma_{y}$, being subjected to three components of principle stresses, $\sigma_{1}, \sigma_{2}$, and $\sigma_{3}$, the Mises yielding condition is expressed by

$$
\left(\sigma_{1}-\sigma_{2}\right)^{2}+\left(\sigma_{2}-\sigma_{3}\right)^{2}+\left(\sigma_{3}-\sigma_{1}\right)^{2}=2 \sigma_{y}^{2}
$$

Here we focus on biaxial stress condition, then $\sigma_{3}$ is eliminated and Eq. (6) can be reduced to

$$
\sigma_{1}^{2}+\sigma_{2}^{2}-\sigma_{1} \sigma_{2}=\sigma_{y}^{2}
$$

As shown in Fig. 2, assuming that a surface cracked plate following elastic-perfectly plastic stress-strain response subjected to the stress parallel to the crack, $S_{x}$, and the stress perpendicular to the crack, $S_{y}$. The directions of $S_{x}$ and $S_{y}$ can be the same as those of $\sigma_{1}$ and $\sigma_{2}$, respectively. The limit load under biaxial stress condition can be determined so that it conforms to the Mises yielding condition. The stress parallel to the crack is not affected by the crack.

$$
\sigma_{1}=S_{x}
$$

The stress perpendicular to the crack is affected by the existence of the crack, and the effect can be taken account through the reference stress, $\sigma_{r e f}$, as a function of $S_{y}$.

$$
\sigma_{2}=\sigma_{r e f}\left(S_{y}\right)
$$

For simplicity, biaxial stress ratio parameter, $R_{s}=S_{x} / S_{y}$, and reference stress ratio parameter, $R_{a}=\sigma_{r e f}\left(S_{y}\right) / S_{y}$, are introduced, principle stresses are then $\sigma_{1}=R_{s} S_{y}$ and $\sigma_{2}=R_{a} S_{y}$. These relations are substituted in Eq. (7), and the yielding condition is

$$
S_{y} \sqrt{R_{a}^{2}+R_{\sigma}^{2}-R_{a} R_{\sigma}}=\sigma_{y}
$$

When the above equation is satisfied at $S_{y}=S_{y, y i e l d}$, the limit load under biaxial loading, $P_{L, \text { biaxial }}$, is given by

$$
P_{L, \text { biaxial }}=2 b t S_{y, \text { yield }}=2 b t \sigma_{y} / \sqrt{R_{a}^{2}+R_{\sigma}^{2}-R_{a} R_{\sigma}}
$$

Putting $S_{x}=0$ (or $R_{s}=0$ ) in Eq. (11), then the limit load under uniaxial loading, $P_{L}$, is obtained by

$$
P_{L}=2 b t \sigma_{y} / R_{a}
$$

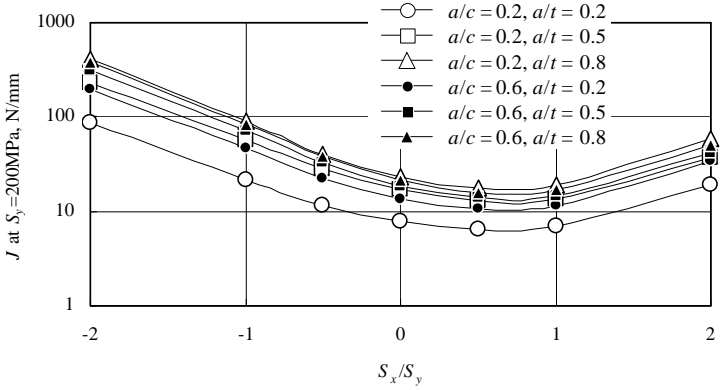

(a) At Deepest Point

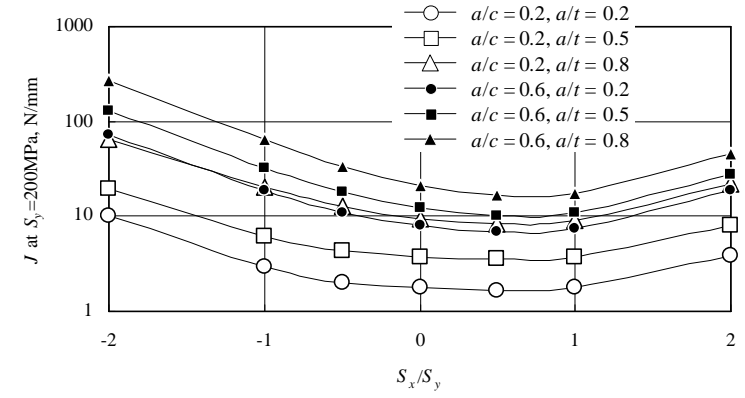

(b) At Surface Point

Fig. 9 Effect of $S_{x} / S_{y}$ on $J$-Integral 
which is identical with the present limit load solutions. As such, the relative variation of limit load due to biaxial loading, $P_{L, b i a x i a l}$ $/ P_{L}$, is given by the following equation.

$$
P_{L, \text { biaxial }} / P_{L}=R_{a} / \sqrt{R_{a}^{2}+R_{\sigma}^{2}-R_{a} R_{\sigma}}
$$

In the above equation, the value of $P_{L, b i a x i a l} / P_{L}$ depends on the reference stress solution used to calculate $R_{a}$. For example, when the Lei's solution in Table 1, which shows good agreement with finite element analysis results under uniaxial loading (see Figs. 1(a) and (b)), is used, $R_{a}$ is given as

$$
R_{a, L e i}=1 /\left[\sqrt{2 \zeta^{2}-2 \zeta+1}-\zeta\right], \quad \zeta=\frac{a}{t} \frac{c}{b}
$$

The relations between $P_{L, \text { biaxial }} / P_{L}$ and $S_{x} / S_{y}$ obtained from Eqs. (13) and (14) are shown in Figs. 10(a) and (b) compared with those obtained from the elastic-perfectly plastic finite element analysis. It is clear that the above equations can describe the dependency on $S_{x} / S_{y}$ for wide range of crack sizes $(a / t$ and $a / c)$. This implies that the limit load under biaxial loading can be well predicted using an appropriate limit load solution under uniaxial loading.

\section{Extended Reference Stress Method under Biaxial Loading} equation,

Based on the reference stress method [6], $J$-integral under elastic-plastic condition can be evaluated by the following

$$
J=\frac{E \varepsilon_{r e f}}{\sigma_{r e f}} J_{e}
$$

where $E$ is the Young's modulus, $\sigma_{r e f}$ and $\varepsilon_{r e f}$ are the reference stress and the reference strain, respectively. The elastic $J$-integral, $J_{e}$, is directly derived from the stress intensity factor, $K_{I}$, and is independent of the stress parallel to the crack.

$$
J_{e}= \begin{cases}\left(1-v^{2}\right) K_{I}^{2} / E, & \text { at the deepest point } \\ K_{I}^{2} / E, & \text { at surface point }\end{cases}
$$

where $v$ is the Poisson's ratio. $K_{I}$ for the plates with a semi-elliptical surface crack subjected to uniform tensile stress, $S_{y}$, can be calculated by the Raju-Newman's stress intensity factor solution [7],

$$
\begin{aligned}
& K_{I}=S_{y} \sqrt{\pi a / Q} F_{s}, \quad F_{s}=\left[M_{1}+M_{2}(a / t)^{2}+M_{3}(a / t)^{4}\right] g f_{\phi} f_{W}, \quad Q=1+1.464(a / c)^{1.65} \\
& M_{1}=1.13-0.09 a / c, \quad M_{2}=-0.54+\frac{0.89}{0.2+a / c}, \quad M_{3}=0.5-\frac{1}{0.65+a / c}+14(1-a / c)^{24} \\
& g=\left\{\begin{array}{ll}
1, & \text { at the deepest point } \\
1.1+0.35(a / t)^{2}, & \text { at surface point }
\end{array}, \quad f_{\phi}=\left\{\begin{array}{ll}
1, & \text { at the deepest point } \\
\sqrt{a / c}, & \text { at surface point }
\end{array}, \quad f_{w}=[\sec (\pi / 2 \cdot c / b \cdot \sqrt{a / t})]^{1 / 2}\right.\right.
\end{aligned}
$$

Postulating that the effect of biaxial loading can be properly taken account through the reference stress as the preceding discussion, it is expected that the reference stress method can be naturally expanded under biaxial loading.

$$
J=\frac{E \varepsilon_{\text {ref,biaxial }}}{\sigma_{\text {ref,biaxial }}} J_{e}
$$

From the proportional relation between the reference stress and the limit load, the reference stress under biaxial loading, $\sigma_{\text {ref,biaxial }}$, can be written as

$$
\sigma_{\text {ref, biaxial }}=\sigma_{\text {ref }} \frac{R_{a}}{\sqrt{R_{a}^{2}+R_{\sigma}^{2}-R_{a} R_{\sigma}}}=\frac{S_{y}}{\sqrt{R_{a}^{2}+R_{\sigma}^{2}-R_{a} R_{\sigma}}}
$$

and $\varepsilon_{\text {ref,biaxial }}$ is the strain corresponding to $\sigma_{\text {ref,biaxial }}$ on the stress-strain relation. 


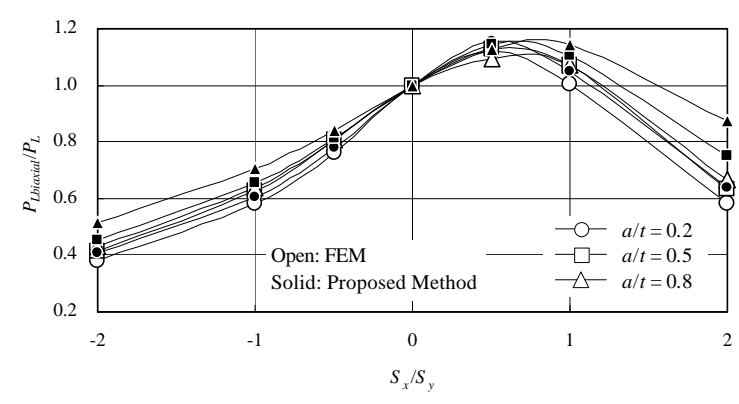

(a) For $a / c=0.2$

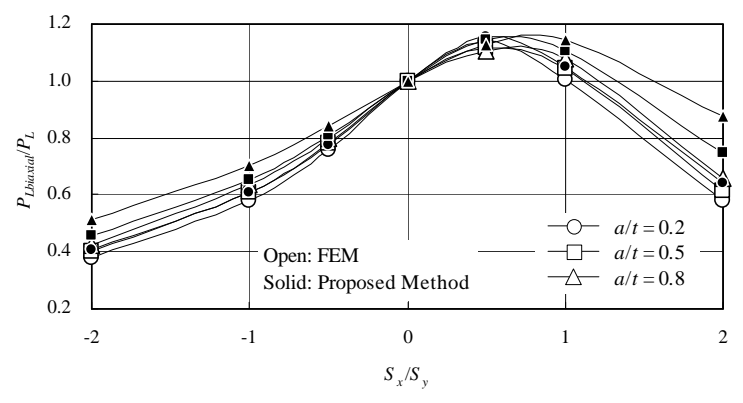

(b) For $a / c=0.6$

Fig. 10 Comparison of Relations between $P_{L b i a x i a l} / P_{L}$ and $S_{x} / S_{y}$ Obtained from Finite Element Analysis and Proposed Method

\section{Validation of Proposed Method}

Figures 11(a) to (c) show the typical comparison of the relations between $J$-integral at the deepest point and $S_{y}$, and Figs. 12 (a) to (c) show the typical comparison of the relations between $J$-integral at the surface point and $S_{y}$, obtained from the proposed method together with the Lei's reference stress solution and finite element analysis. Cases for $S_{x} / S_{y} \leq 0$ and $S_{x} / S_{y} \geq 0$ are separately presented to avoid complexity. The proposed method gives a satisfactory prediction of $J$-integral at the deepest point. It also predicts favorable $J$-integral at surface point in most cases, however, predicted values seem to be conservative for negative $S_{x} / S_{y}$.

Figures 13(a) and (b) examine the accuracy of $J$-integral evaluated by the proposed method together with the Lei's reference stress solution by plotting $J$-integral normalized in relative to the finite element analysis results. The normalized $J$ is close to unity for most cases, which suggests that the proposed method generally works well. Exceptionally, the normalized $J$ at the surface point is significantly larger in the case of $S_{x} / S_{y}$ less than -1 , nevertheless, the method gives conservative predictions in the meantime.

\section{CONCLUSIONS}

In this paper, reference stress solutions for plates with a semi-elliptical surface crack were reviewed. The applicability of the solutions was examined through the comparison with finite element analysis results under uniaxial loading, and the Lei's solution could be the most appropriate reference stress solution. Next, an extended reference stress method has been derived to evaluate $J$-integral for cracked plates under biaxial loading by modeling yielding condition under biaxial loading. It was ascertained through the comparison with finite element analysis results that the proposed method together with the Lei's
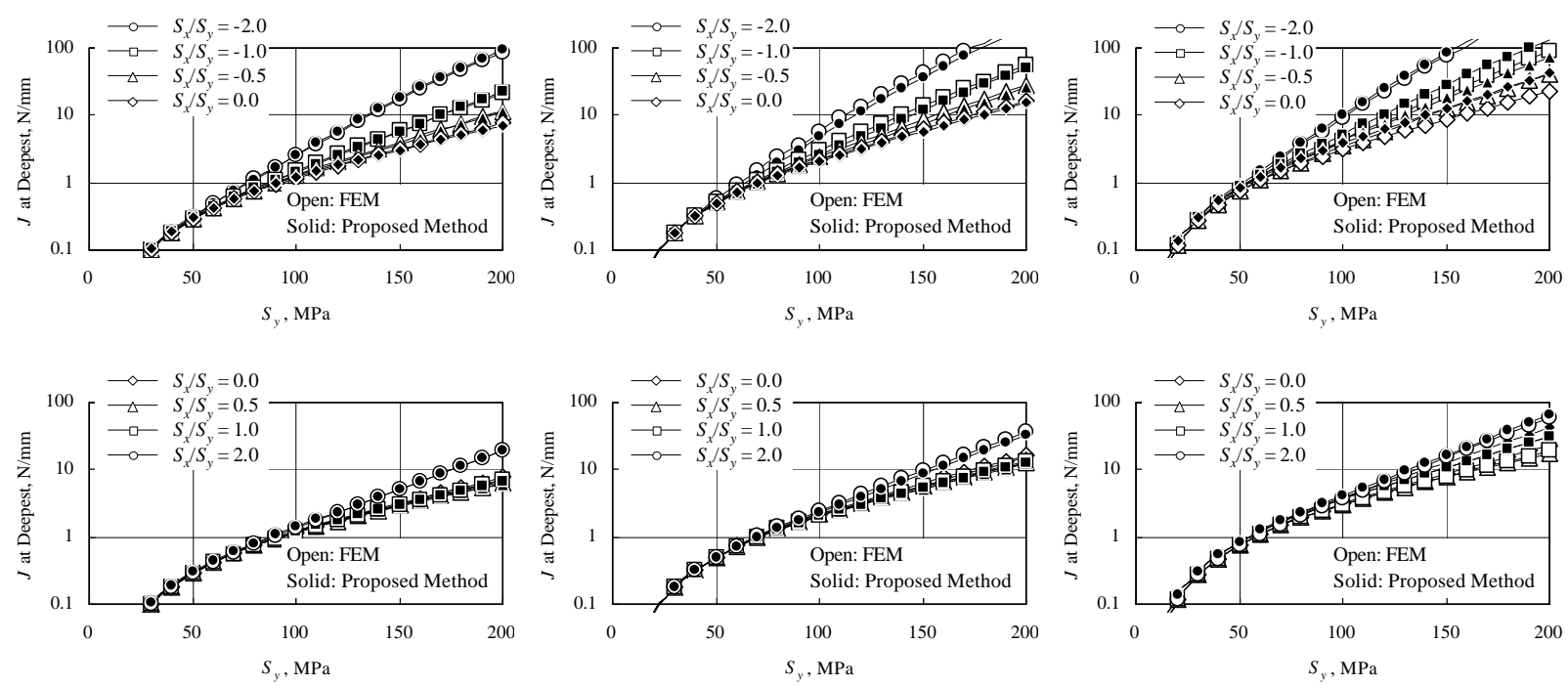

(a) Case $1(a / c=0.2, a / t=0.2)$

(b) Case $2(a / c=0.2, a / t=0.5)$

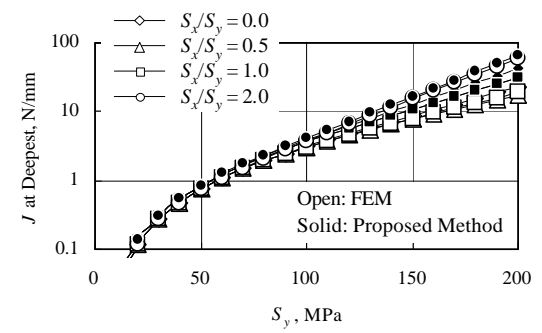

(c) Case $3(a / c=0.2, a / t=0.8)$

Fig. 11 Typical Comparison of Relations between $J$-Integral at Deepest Point and $S_{y}$ 

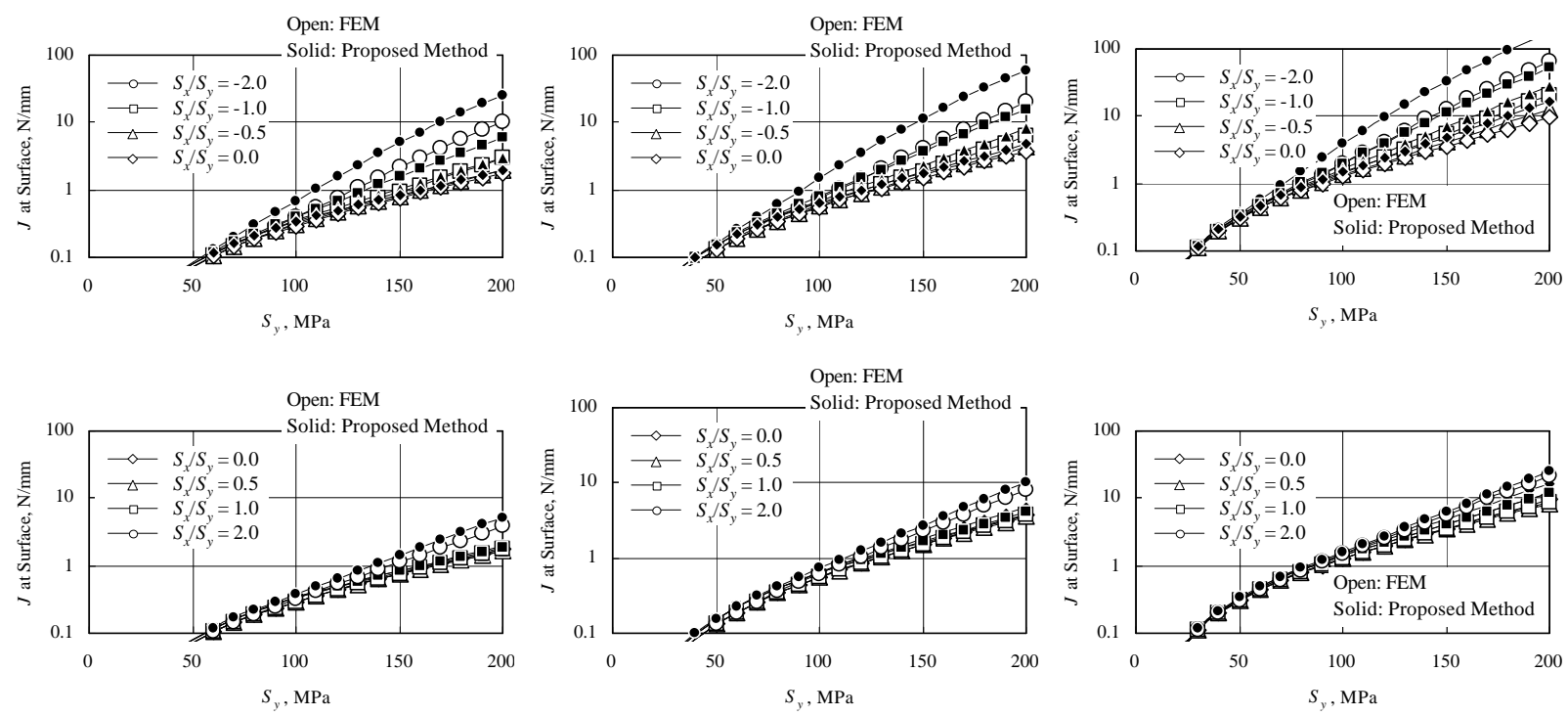

(a) Case $1(a / c=0.2, a / t=0.2)$

(b) Case $2(a / c=0.2, a / t=0.5)$

(c) Case $3(a / c=0.2, a / t=0.8)$

Fig. 12 Typical Comparison of Relations between $J$-Integral at Surface Point and $S_{y}$

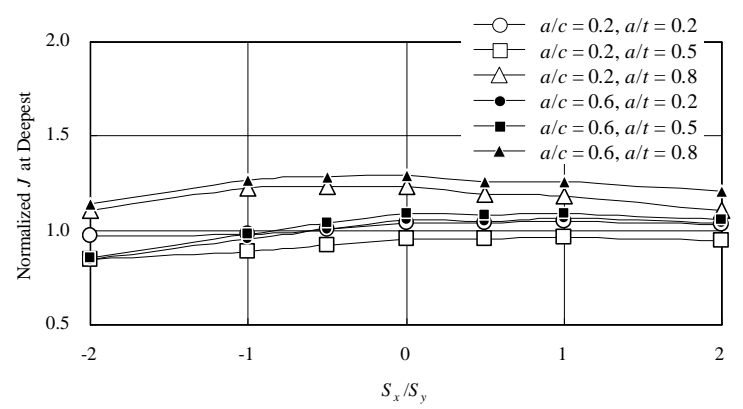

(a) At Deepest Point

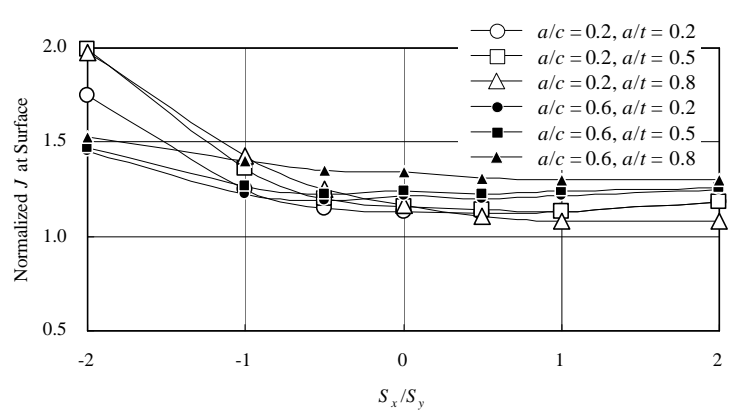

(b) At Surface Point

Fig. 13 Relative Comparison of $J$-Integral Evaluation Accuracy (Finite Element Analysis Results = 1)

reference stress solution predicts $J$-integral with acceptable accuracy.

\section{REFERENCES}

1. Willoughby, A. A. and Davey, T. G., "Plastic Collapse in Part-Wall Flaws in Plates," ASTM STP 1020, 1989, pp. $390-409$.

2. Sattari-Far, I., "Finite Element Analysis of Limit Loads for Surface Cracks in Plates," International Journal of Pressure Vessels and Piping, Vol. 57, 1994, pp. 237-243.

3. Sattari-Far, I. and Dillstrom, P., "Local Limit Load Solutions for Surface Cracks in Plates and Cylinders Using Finite Element Analysis," International Journal of Pressure Vessels and Piping, Vol. 81, 2004, pp. 57-66.

4. Goodall, I. W. and Webster, G. A., "Theoretical Determination of Reference Stress for Partially Penetrating Flaws in Plates," International Journal of Pressure Vessels and Piping, Vol. 78, 2001, pp. 687-695.

5. Lei, Y., "J-Integral and Limit Load analysis of Semi-Elliptical Surface Cracks in Plates under Combined Tension and Bending," International Journal of Pressure Vessels and Piping, Vol. 81, 2004, pp. 43-56.

6. Ainsworth, R. A., "The Assessment of Defects in Structures of Strain Hardening Materials," Engineering Fracture Mechanics, Vol. 19, 1984, p. 633.

7. Newman, J. C. and Raju, I. S., "Stress-Intensity Factor Equations for Cracks in Three-Dimensional Finite Bodies Subjected to Tension and Bending Loads," NASA Technical Memorandum 85793, 1984. 